\title{
Correction to: Fractal dimension brain morphometry: a novel approach to quantify white matter in traumatic brain injury
}

\author{
Venkateswaran Rajagopalan ${ }^{1,2} \cdot$ Abhijit Das $^{2,3} \cdot$ Luduan Zhang $^{4} \cdot$ Frank Hillary $^{5} \cdot$ Glenn R. Wylie $^{2,3} \cdot$ Guang H. Yue $^{2,6}$ \\ Published online: 3 November 2020 \\ (C) Springer Science+Business Media, LLC, part of Springer Nature 2020
}

\section{Correction to: Brain Imaging and Behaviors (2019) 13:914-924 https://doi.org/10.1007//11682-018-9892-2}

The original published version of this article contained mistakes. The author noticed that figure captions/legends got mismatched with the figures.

Below are the corrections:

Figure 1 caption should go with Figure 4 Figure 2 caption should go with Figure 1 Figure 3 caption should go with Figure 2 Figure 4 caption should go with Figure 3

Publisher's note Springer Nature remains neutral with regard to jurisdictional claims in published maps and institutional affiliations.

The online version of the original article can be found at https://doi.org/ $10.1007 / \mathrm{s} 11682-018-9892-2$

Venkateswaran Rajagopalan

venkatnrp78@gmail.com

$\bowtie$ Guang H. Yue

gyue@kesslerfoundation.org

1 Department of Electrical and Electronics Engineering, Birla Institute of Technology and Science, Pilani, Hyderabad Campus,

Hyderabad, India

2 Department of Physical Medicine and Rehabilitation, Rutgers New Jersey Medical School, Rutgers, the State University of New Jersey, Newark, NJ 07103, USA

3 Neuroscience and Neuropsychology Research, Kessler Foundation, 120 Eagle Rock Avenue, East Hanover, NJ 07936, USA

4 LZ Biomedical Inc., Westminster, CO 80021, USA

5 Department of Psychology, Pennsylvania State University, 313 Moore Building, University Park, PA 16801, USA

6 Human Performance and Engineering Research, Kessler Foundation, 1199 Pleasant Valley Way, West Orange, NJ 07052, USA 